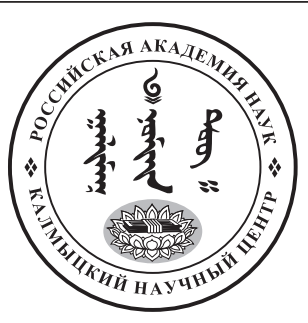

Published in the Russian Federation

Oriental Studies (Previous Name: Bulletin of the Kalmyk Institute

for Humanities of the Russian Academy of Sciences)

Has been issued as a journal since 2008

ISSN: 2619-0990; E-ISSN: 2619-1008

Vol. 14, Is. 6, pp. 1281-1289, 2021

Journal homepage: https://kigiran.elpub.ru

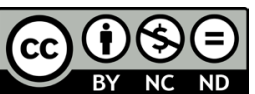

УДК / UDC 39. 395

DOI: 10.22162/2619-0990-2021-58-6-1281-1289

\title{
Организация жилого пространства в традиционном этикете башкир
}

\section{Розалия Рафкатовна Баязитова ${ }^{1}$}

${ }^{1}$ Институт истории, языка и литературы Уфимского федерального исследовательского центра РАН (д. 71, просп. Октября, 450054 Уфа, Российская Федерация) кандидат исторических наук, доцент, старший научный сотрудник iD 0000-0002-5731-2019.E-mail: rosali8@mail.ru

\author{
(C) КалмНЦ РАН, 2021
}

(С) Баязитова Р. Р., 2021.

\begin{abstract}
Аннотация. Введение. В традиционной культуре важное значение придавали проксемическому поведению. В статье представлены результаты исследования структурирования жилища, соблюдения этноэтикета в рамках традиционного жилого пространства башкир. Целью исследования явилось изучение структуры жилого пространства, его предметного содержания и стилистики поведения в жилище. Maтериаль и методы. Источниками подготовки представленной статьи послужили неопубликованные полевые материалы автора, также опубликованные фольклорные тексты, сообщения участников академических экспедиций XVIII в., в которых содержатся ценные сведения о временных и постоянных жилищах башкир. Для достижения поставленной цели были применены сравнительно-исторический, типологический, структурно-семантический, описательный методы исследования. Хронологические рамки исследования охватывают XVIII - начало XX вв. Результаты. На основе проведенного исследования можно сделать вывод о том, что структурирование жилого пространства тесно связано с древними верованиями, религией, этнической историей. Вертикальная и горизонтальная детализация частей жилища и анализ распределения пространства внутри юрты показывает, что жилище башкирами воспринималось как модель мира. Горизонтальное структурирование внутреннего пространства было связано с древними познаниями башкир о сторонах света, затем оно обогатилось мусульманским учением. Поведение башкир в помещении строилось согласно структурно-семантической модели жилища, освоенного пространства в целом. Традиционным этикетом регламентировалось поведение индивида в рамках жилого помещения согласно половозрастному статусу и социальному положению. Жилище определяло область окультуренного, защищенного пространства, отделяло «свое» от «чужого», согласно структуре внутреннего пространства, создавало условия для вариативного поведения. В помещении поведение членов семьи, гостей строилось согласно бинарным оппозициям: «левая - пра-
\end{abstract}


вая», «мужская - женская», «почетная - менее почетная», «гостевая - хозяйственная», «верх - низ», «центр - периферия».

Ключевые слова: традиционный этикет башкир, юрта, почетное место, структура жилища, очаг, правая сторона, левая сторона

Благодарность. Исследование проведено в рамках государственной субсидии - проект «Духовная культура тюркских народов Южного Урала» (номер регистрации: АААА-А17-117040350082-3).

Для цитирования: Баязитова Р. Р. Организация жилого пространства в традиционном этикете башкир // Oriental Studies. 2021. Т. 14. № 6. C. 1281-1289. DOI: 10.22162/2619-0990-2021-58-61281-1289

\title{
Living Space Structure in Bashkir Traditional Etiquette
}

\author{
Rozaliya R. Bayazitova
}

${ }^{1}$ Institute of History, Language and Literature, Ufa Federal Research Centre of the RAS (71, Oktyabrya Ave., 450054 Ufa, Russian Federation)

Cand. Sc. (History), Associate Professor, Senior Research Associate

iD 0000-0002-5731-2019. E-mail: rosali8@mail.ru

\author{
(C) KalmSC RAS, 2021
}

(C) Bayazitova R. R., 2021

\begin{abstract}
Introduction. In traditional culture, proxemic behavior is of great importance. The article is based on the results of the research on the structuring of the dwelling and the observance of ethnoetiquette norms within the framework of the traditional living space of the Bashkirs. The aim was to study the structure of the living space, interiors, and the stylistics of behavior in the traditional dwelling. Materials and methods. The main research sources were the author's unpublished field materials, as well as published folklore texts, reports of the participants of academic expeditions of the 18th century, which contain valuable information about the temporary and permanent dwellings of Bashkirs. Methods used for the analysis were comparative-historical, typological, structural-semantic, and descriptive. The chronological framework of the study covers the period between the 18th and early 20th centuries. Results. The research shows that the structuring of living space is closely related to ancient beliefs, religion, and the ethnic history of the people. Vertical and horizontal divisions of the dwelling and analysis of space distribution inside the yurt indicate that the dwelling was perceived as a model of the world. The horizontal structuring of the inner space was associated with the ancient knowledge of the Bashkirs about the cardinal points, later enriched with Muslim teachings. In their behavior in the interiors, the Bashkirs were guided by the structural-semantic model of the dwelling, the entire developed space. In this aspect, gender, age, and social status were important factors of the traditional etiquette. The dwelling represented a cultivated, protected space, separating "one's own" space from "other's", according to the structure of the internal space, and creating conditions for variable behavior; family members and guests followed binary oppositions, such as left versus right, male versus female, honorable versus less honorable, the parts for guests and household activities, top and bottom, center and periphery.
\end{abstract}

Keywords: traditional Bashkir etiquette, yurt, place of honor, dwelling structure, hearth, right side, left side

Acknowledgements. The reported study was funded by government subsidy, project no. AAAA-A17-117040350082-3 'Turkic Peoples of the Southern Urals: Spiritual Culture'.

For citation: Bayazitova R. R. Living Space Structure in Bashkir Traditional Etiquette. Oriental Studies. 2021; 14 (6): 1281-1289. (In Russ.) DOI: 10.22162/2619-0990-2021-58-6-1281-1289 


\section{Введение}

В традиционном обществе поведение человека строилось с учетом пространственно-временных представлений. Эти категории у разных народов наделялись определенной смысловой нагрузкой. Согласно Н. Л. Жуковской: «Пространство и время важнейшие категории культуры, образующие основную систему координат, в рамках которой возникают, функционируют и развиваются мифология, религия, искусство, наука» [Жуковская 2002: 13]. Названные категории, обусловленные хозяйственной деятельностью, климатом, особенностями мировоззрения и бытия народа, являются важными составляющими этикета, согласно которым определялись нормы и правила поведения человека в объективных физических условиях.

В процессе общения людей важное значение придавалось проксемическому поведению индивидов. В представленной статье рассмотрим некоторые особенности организации жилого пространства в традиционном этикете башкир. Изучению традиционных поселений и жилищ башкир посвящено монографическое исследование С. Н. Шитовой [Шитова 1984].

В трудах отдельных башкирских исследователей раскрываются особенности временных и постоянных жилищ, интерьера и экстерьера жилых помещений [Руденко 2006; Калимуллин 1959; Юсупов 2010; Янбухтина 1993]. В то же время в работах названных авторов вопросы взаимосвязи структуры жилища и культуры поведения, этикета затронуты поверхностно.

Организация жилого пространства, семантика жилища, некоторые вопросы проксемического поведения восточнославянских, монгольских, тюркских народов подробно изучены в трудах отечественных ученых [Байбурин 1983; Бакаева, Сангаджиев 2005; Жуковская 2002; Салмин 1998; Шараева 2020] и др.

Целью настоящего исследования является изучение структуры жилого пространства, его предметного содержания и моделей поведения членов семьи. Как известно, участники этикетной ситуации соблюдали не только дистанцию, но и учитывали взаимное расположение людей в помещении.

Организация пространства важна и в ритуале, и в повседневной жизни. А. К. Байбурин отмечает: «...жилище и обряд являются конкретными реализациями картины мира», «жилище может быть включено в структуру ритуала» и также «может выступать в качестве основного объекта ритуала» [Байбурин 1983: 14]. Подобный комплекс связей между человеком и жилым пространством характерен и для этикета. Как известно, этническая картина мира, проявляемая в языке, религиозных представлениях, этнических константах в целом, нашла отражение в постройке жилых помещений, определяла социальное поведение людей. Жилище, включенное в этикет, задавало тон, согласно структуре внутреннего пространства, создавало условия для вариативного поведения.

\section{Материалы и методы}

Источниками исследования послужили неопубликованные полевые материалы автора, сообщения участников академических экспедиций XVIII в. Для изучения структуры жилого пространства, его предметного содержания и моделей поведения членов семьи были применены сравнительно-исторический, типологический, структурно-семантический, описательный методы исследования.

\section{Общие замечания}

Башкиры, как и многие полукочевые народы Евразии, более половины своей жизни проводили во временных жилищах. Традиционно места для поселений выбирали с учетом наличия воды, пастбищ и естественных укрытий для скота. Родственники селились компактно, что способствовало укреплению их взаимоотношений, формированию чувства причастности к большому роду.

По наблюдениям С. И. Руденко, у башкир встречались разные виды жилищ, которые он распределил на две обширные категории: временные и постоянные. К временным постройкам, например, С. И. Руденко относил шалаши (бесән кыууыш, киндер кы- 
уыли, каравас кабызы, укбаш), деревянные кибитки (авас тирмә), балаганчики из досок (такта аласык), летние срубные жилища (бурама) и другие сооружения [Руденко 2006: 172-185]. Зимой башкиры жили в домах, которые сооружались в виде простых срубов, для их постройки использовались строительный лес, камень, глина, дерн, камыш, солома, тальник.

Как отмечает С. Н. Шитова: «Люди старшего поколения в качестве основных жилищ на летовках в большинстве случаев называют юрту или бревенчатые домики» [Шитова 1984: 129]. У башкир была распространена юрта (тирмд) двух типов: монгольская и тюркская. Цвет кошмы юрты указывал на статус ее владельца. Белый цвет войлока символизировал достаток, темный войлок был характерен для жилищ менее состоятельных хозяев. Остов юрты состоял из шести, двенадцати деревянных складных решеток. Купол изготавливали из вогнутых жердей, верхний конец которых вставлялся в брусчатый обод, жилище покрывали войлоком, деревянная дверь была одно- или двустворчатой. Легкость при транспортировке и установке, устойчивость и способность сохранять тепло и прохладу в различных погодных условиях делали юрту идеальным жилищем.

О названии тирмә Р. М. Юсупов писал следующее: «Понятие решетка в древней форме тереме теребе сохранилось у тувинцев, алтайцев, туркмен (терим). В то же время у башкир под словом тирме понимается общее название юрты, а решетка называется канат. По нашему мнению, понятие юрта как временное жилище вошло в русский язык от названий сезонных стоянок башкир-скотоводов, на которых ставились решетчатые куполообразные жилища: весенняя стоянка (язљљь йорт), летовка (йәйге йорт), осенняя стоянка (көз̧гө йорт)» [Юсупов 2010: 10].

Будучи одним из важных объектов материальной культуры, в традиционном обществе жилище (временное, постоянное) выполняло различные функции. Так, Т. И. Шараева описала следующие функции: «Традиционное кочевое жилище калмыков, как и у других тюрко-монгольских номадов, обладало рядом функций: создавало комфорт для проживания в условиях кочевой жизни, обеспечивало защиту от природных стихий, являлось символической и магической моделью, через которую выстраивалась связь человека с вертикальным и горизонтальным членением окружающего мира. В архаических представлениях номадов жилище также было связано с различными культами: огня, предков, земли, неба и т. д.» [Шараева 2020: 43]. Развитие жилища, его внутреннее убранство, внешнее оформление, конструкция жилища и распределение пространства в нем тесно связаны с особенностями семейного и общественного этикета.

Правила поведения в жилом пространстве, сложившиеся на протяжении веков, регулировали взаимоотношения между членами семьи, гостями согласно полу, возрасту и статусу. Поведение внутри жилища обусловлено также составом семьи. О взаимосвязи структуры семьи и жилища С. А. Токарев писал: «Но каков бы ни был семейный или иной коллектив, обитающий в жилище, он всегда имеет свою структуру, и эта структура непременно отражается, порой существенным образом, и на типе постройки, и на соотношении ее частей, и на распределении предметов обстановки интерьера, на функционировании отдельных помещений, комнат, углов» [Токарев 1970: 15-16].

Строение и распределение внутреннего пространства юрты практически одинаково у многих народов, у которых зафиксирован данный вид жилища, в то же время наблюдаются некоторые особенности, обусловленные этнической историей, верованиями и религией, климатическими условиями. Общее и особенное в жилище разных народов проанализировано Э. П. Бакаевой и Ю. И. Сангаджиевым: «Второстепенные характеристики обладают этнодифференцирующими свойствами, которые позволяют разграничить однотипные конструкции жилища, присущего культурам различных народов» [Бакаева, Сангаджиев 2005: 18].

\section{Этикетная проксемика}

Вертикальная и горизонтальная детализация составных частей и анализ распределения пространства юрты между участниками общения показывает, что в прошлом строение жилища воспринималось как модель мира. Поведение башкир строилось согласно структурно-семантической модели жилища, освоенного пространства в целом. Горизонтальное структурирование внутрен- 
него пространства было связано с древними познаниями башкир о сторонах света, затем оно обогатилось мусульманским учением. Эти знания нашли отражение в определении почетного места, установлении составных частей жилища (двери, например) и, соответственно, в структурировании внутреннего пространства жилища и т. п.

Рассмотрим некоторые примеры. В юрте члены семьи и гости занимали место, соответствующее их половозрастному, семейному и общественному статусу - от менее почетного места (ближе к двери) к почетному түр (напротив двери). Почетное место в башкирской юрте ( напротив входа, обозначалось оно постельными принадлежностями (каралды, түр юрzан). ТYр могли занимать старшие по статусу, возрасту. Чаще всего это место хозяина, главы семьи, почетного гостя, муллы, причем гостей на почетное место усаживал хозяин дома. Позднее, как и в юрте, гостевая, обрядовая трапезы в домах всегда проходили в $т ү р$ як - почетной стороне избы.

Относительно «правой - левой» частей юрты существуют разные точки зрения, которые возникают из-за разногласий по исходной точке описания внутренней планировки. «По тюркской традиции внутреннее членение юрты велось от человека, сидящего в тор (расположен в противоположной от двери самой отдаленной от входа части юрты) и ориентированного лицом на восток. В таком случае он жак будет находиться по правую руку, а сол жак - по левую руку сидящего в тор человека, что и соответствует действительному положению вещей», отмечает казахский ученый А. Т. Толеубаев [Толеубаев 2000: 167].

Такое структурирование юрты соответствует горизонтальному делению пространства, принятому у башкир, где правая сторона - правильная, почетная. Сейчас утвердилось и бытует иное представление: левая часть от входа - мужская, почетная часть, правая часть - женская, хозяйственная. С. Н. Шитова отмечает: «...выделение женской половины было в некоторой мере условным. Занавес, разделяющий части жилища, задергивали лишь при гостях или на ночь. За ним могли спать взрослые дети или женатый сын с невесткой» [Шитова 1984: 135].

Размещение важных бытовых предметов вдоль стен, подвижные занавески обеспечи- вали простор внутри юрты. Полы держали в чистоте, так как нельзя было осквернять, загрязнять место, где отдыхают, принимают пищу. «Кочевник иначе относился к пространству пола в юрте. Воспринимал его иначе, чем живущий в избе. Вся его жизнь проходила на полу, где ели, спали, отдыхали, принимали гостей. Поэтому пол в его представлении должен быть безупречно чистым, теплым, мягким, уютным. Во сколько бы слоев ни был застлан пол кошмами, паласами и другими мягкими предметами, но каждому, особенно гостям, предлагали еще отдельный маленький коврик, а пожилым, старым еще непременно и подушку» [Янбухтина 1993: 44].

Постоянное жилище башкир сохранило традиции распределения и организации пространства кочевого, полукочевого быта. Размещение вещей и разделение жилой площади на мужскую - почетную, женскую хозяйственную части, характерные для юрты, сохранились и в избах.

Особенное значение башкиры придавали месту постройки нового дома. Запрещалось строить дом там, где проходила дорога, - дома на таких местах подвергаются пожарам; нельзя ставить дом на свалках, заброшенных местах, перекрестках - жильцов такого дома будут беспокоить тревога, страшные сновидения [ПМА 2003].

Место старой бани считалось непригодной для новостройки. Похожие представления наблюдались и у восточнославянских народов. Согласно А. К. Байбурину, «ритуальная нечистота бани подчеркивается в системе христианских верований отсутствием икон, что само по себе является значимым» [Байбурин 1983: 36].

Рассмотрение оппозиций «внутренний внешний», «свой - чужой», «закрытый открытый» поможет представить правила поведения в рамках жилого простанства. С. А. Токарев писал: «Уже одни неписаные законы приличия налагают на человека неодинаковые нормы поведения в своем доме и вне его: дома можно быть одетым не так, как „на людях“ (одежда „горничная“ и „выходная“"), совершать действия, не считаемые приличными вне дома» [Токарев 1970: 14].

Как любой «переход через границу», вход в помещение и выход из дома регулировались запретами и предписаниями. 
Например, нельзя заходить в чужой дом с правой ноги, особенно в первый раз, с пустой посудой, возвращать пустую вещь, где можно что-то хранить. При первичном посещении чужого дома обязательно читают молитву, приносят подарки, произносят благопожелания. Запрещалось выносить за пределы своего пространства определенные предметы, боясь потерять кот 'благополучие', особенно после заката солнца, например: выносить горящие головешки, тушить их, после заката отдавать молоко за пределы дома и т. п. Через порог нельзя здороваться, передавать предметы, хлопать дверью, стоять, сидеть, стоять на пороге. Пожилые постоянно предупреждают: «Порог может проклясть» [ПМА 2003; ПМА 2017].

Если жилище служило защитой человека от разных опасностей, то выход из него можно рассматривать как переход в неосвоенный мир. Порог и дверь являются границей двух семантических пространств: «свое чужое». Подчеркивая символическое значение отдельных предметов быта, явлений природы, обозначения сторон света, чисел, цвета, 3. Г. Ураксин писал, что на них существуют определенные запреты, и они имеют магическую силу охраны, излечения от болезней, недугов, сглаза. Например, нельзя сидеть и стоять на пороге (останешься сиротой, несчастным), через порог нельзя передавать в руки вещи и принимать их [Ураксин 2000: 75].

До сегодняшних дней в жилом помещении место у двери считается наименее почетным местом. Пограничное состояние двери четко проявляется в повседневной жизни и обрядах. Элементы двери применяются в народной медицине: «Магический способ лечения от сглаза. КҮз тейhə, ишек тоткаларын сайып күзеккән кешегә сайblнды hөртәләр. 'При сглазе споласкивают ручки дверей и этой водой обтирают больного'» [Хисамитдинова 2010: 259].

Дверь была входом для всевозможных злых духов. Для предотвращения беды в дверной косяк втыкали ветку можжевельника, металлические предметы. На ночь, закрывая дверь на засов, обязательно произносится: «Во имя Аллаха Милостивого, Милосердного». В противном случае домашним будут сниться кошмары. Согласно поверьям, шайтан не выговаривает «р» и поэтому не может произнести «Бисмилла- хи-р-рахмани-р-рахим» и проникнуть в дом: Төнө буйь ииек төбөндә: «Бисилла-бисилла», - тип торалар, ти 'Всю ночь шайтаны могут простоять у двери, проговаривая: «Бисилла-бисилла»' [ПМА 2003]. В данном случае первые слова молитвы охраняют жилище от нечистой силы.

Исходя из представления о пограничном состоянии двери, ворот, до сих пор сохранился запрет распахивать ворота, что означает смерть близких (домашних, членов семьи). В то же время необходимо отметить, что двери юрты, деревянных изб не запирались на замок. По полевым данным, только после 90-х гг. прошлого века двери, ворота начали запирать на ключ.

\section{Некоторые символы жилого про-} странства

В традиционной башкирской избе печь и нары были главными ориентирами поведения: мейес янында 'у печки', артында 'за печкой', башында 'на печи' и т. п. В организации интерьерного пространства башкирской избы большую роль играет печь, отмечает А. Г. Янбухтина. Всегда свежевыбеленная, убранная пестрыми ситцевыми занавесками (и в верхней части, и по бокам), она - доминирующая пластическая форма в доме, где все и вся организовано в соответствии и по отношению к ней [Янбухтина 1993: 98]. Выбеленная печь была критерием чистоплотности хозяйки дома, печному пространству присваивали женский статус - катылдар явы 'женская сторона', au-hbly яzbl 'место приготовления пищи' и т. п. Появление мужчин на женской стороне было нежелательно. Огонь, зажжённый в печи, был знаком того, что жизнь в доме идет своим чередом. В народе бытует следующий афоризм: «Встав с постели, в первую очередь взгляни на трубу соседа». Если дым идет, то с соседями все нормально. У башкир сохранилось также такое словосочетание уm күрше 'самый близкий сосед'. В прошлом, когда не было спичек, у рядом живущих соседей брали горящие угли для разведения огня. Возможно, это выражение отсюда берет начало, но смысл, вкладываемый в него, значительно шире.

Наряду с основными функциями - производство тепла, еды, обеспечение безопасности и уюта, печь выполняла символическую функцию. Устье, дымоход воспринимались как пограничное пространство меж- 
ду мирами. Не случайно при совершении ритуала, магических приемов лечения, знахарки обращаются с просьбами к высшим силам через дымоход, как шаманы, которые выходили на связь с духами по дымовому отверстию юрты. Например, для избавления ребенка от родинок: «В Зилаирском, Хайбуллинском р-нах отец ребенка, пожилая женщина, белолицая девушка или чей-то ребенок кричали в печную трубу имя с добавлением слова миң, например, Миңнихәмдия, чтобы родинка исчезла. Это повторялось несколько раз» [Бикбулатов, Фатыхова 1991: 107]. Во время грозы закрывают вьюшку, опасаясь удара молнии. Молния в мифологическом понимании - это наказание свыше.

В жилом помещении отмечались особые места, которые были связующим звеном между миром живых и умерших. «Во многих домах у башкир рядом с дверью был вбит деревянный колышек (аzас сөй) для души покойного. Считалось, что душа могла прилетать и садиться туда. Она могла поселиться и на перекладине (урзза)» [Башкиры 2002: 215].

Аналогичные специальные детали внутри жилого помещения замечены и у других родственных башкирам народов. «В представлении казахов тор не только почетное место, но и сакральное. Раньше тул - заместитель умершего в течение года после смерти человека - ставился в тор» [Толеубаев 2000: 167].

У алтайцев выделялись места локализации божеств - хранителей юрты: «Налево от постели футов на восемь пол и мешки покрыты коврами. Над коврами с жердей крыши свисают фигурки божков: круглые деревянные обручи шириной в два дюйма, с вписанной в них фигуркой с растопыренными руками и ногами, да еще заячьи шкурки, обернутые в войлок, перевязанные крест-накрест шнуром и подвешенные внутри такого же обруча. Зачем с горизонтально натянутого шнура свисают девять пестрых ленточек или лоскутков, средний из которых вырезан в виде человека или животного? Эти лоскутки называются сомо. А вообще все божки называются в народе кудай (бог) ... перед многими юртами на двух шестах натянут шнур, на котором висит множество пестрых тряпочек. Такой шнур тоже называется сомо. Как мне удалось уз- нать, лоскутки сомо означают девять предков или духов - хранителей юрты. Я никогда еще не видел, чтобы алтаец оказывал своим божкам в переднем углу какие-либо знаки почитания» [Радлов 1989: 141-142].

У чувашей, по данным А. К. Салмина, «столб у печи является локусом, олицетворяющим покойников» [Салмин 1998: 43].

Отдельные бытовые предметы символизировали отчий дом. Например, у башкир символом родительского дома считался кожаный сосуд һаба. Значение һаба подчеркнуто И. Г. Георги: «Когда напоследок жених собирается вести невесту свою домой, то она ходит из юрты в юрту прощаться с благодарением и плачем; и при сем случае наделяют ее иные скотом, а иные домашнею рухлядью. В родительской юрте обнимает она кумызный мешок, благодарит ему, что столь долго ее питал, и прицепляет к нему небольшой подарок» [Георги 1799: 106].

Особенное отношение к жилищу проявлялось в том, что оно относилось к не отчуждаемому имуществу, т. е. посторонним людям его не дарили, старались сохранить ата йорто 'отчий дом'. Согласно минорату, отцовский дом у башкир наследовал младший сын, тем самым обеспечивал пожилым родителям уход и заботу. «Поэтому неслучайно в номенклатуре родства башкир имеется специальный для него термин кинйә / кинжә, төпсөк», - отмечали исследователи [Бикбулатов, Фатыхова 1991: 145]. Заметим, свою долю от отцовского имущества старший сын получал после женитьбы. В традиционном обществе наличие отдельного жилища подтверждало самостоятельность мужчины, так как женщины проблемами обзаведения жилья не занимались.

\section{Заключение}

Древние верования и религия, нравственные нормы легли в основу структурирования жилого помещения, правил поведения в жилище. Традиционный этикет регламентировал поведение каждого члена семьи в рамках жилого пространства согласно его статусу. Деление жилого пространства тесно связано с представлениями этноса о картине мира, идеологией общества определенной эпохи, нравственными принципами.

Поведение вне и внутри дома отличалось. Именно в рамках освоенного пространства происходила социализация, осуществлялась трансляция этикета, выполня- 
лись домашние работы и т. п. Внутреннее убранство, внешнее оформление, конструкция жилища и распределение пространства в нем тесно связаны с особенностями семейного и общественного этикета. Жилище определяло область окультуренного, защищенного пространства, отделяло «свое» от «чужого», согласно структуре внутреннего пространства, создавало условия для вари-

\section{Полевые материалы автора}

ПМА 2003; ПМА 2017 - Экспедиция в Баймакский, Белорецкий, Бурзянский, Кугарчинский районы Республики Башкортостан. 2003-2017 гг.

\section{Литература}

Байбурин 1983 - Байбурин А. К. Жилище в обрядах и представлениях восточных славян. Л.: Наука, ЛО, 1983. 191 с.

Бакаева, Сангаджиев 2005 - Бакаева Э. П., Сангаджиев Ю. И. Культура жилища: этнические традиции и современные приоритеты у калмыков. Элиста: Джангар, 2005. 196 с.

Башкиры 2002 - Башкиры: этническая история и традиционная культура / Н. В. Бикбулатов, Р. М. Юсупов, С. Н. Шитова, Фатыхова Ф. Ф.; под общ. ред. Р. М. Юсупова. Уфа: Башкирская энциклопедия, 2002. 248 с.

Бикбулатов, Фатыхова 1991 - Бикбулатов Н. В., Фатыхова Ф. Ф. Семейный быт башкир. XIX-XX вв. М.: Наука, 1991. 189 с.

Георги 1799 - Георги И. Г. Башкирцы // Описание всех обитающих в Российском государстве народов и их житейских обрядов, обыкновений, одежд, жилищ, вероисповеданий и прочих достопамятностей. Часть вторая. О народах татарского племени и других не решенного еще происхождения Северных Сибирских. СПб.: Имп. АН, 1799. С. 93-108.

Жуковская 2002 - Жуковская Н. Л. Кочевники Монголии: Культура. Традиции. Символика: Учебное пособие. М.: Вост. лит., 2002. $247 \mathrm{c}$.

Калимуллин 1959 - Калимуллин Б. Г. Планировка и застройка башкирских деревень. Уфа: Баш. кн. изд-во, 1959. 108 с.

Радлов 1989 - Радлов В. В. Из Сибири: Страницы дневника / пер с нем. К. Д. Цивиной и Б. Е. Чистовой; прим. и послесл. С. И. Вайнштейна. М.: ГРВЛ, 1989. 749 с.

Руденко 2006 - Руденко С. И. Башкиры: Исто- ативного поведения. В помещении поведение членов семьи, гостей строилось согласно бинарным оппозициям: «левая - правая», «мужская - женская», «почетная - менее почетная», «гостевая - хозяйственная», «верх - низ», «центр - периферия». Жилище относилось к неотчуждаемой собственности. Дом был символом самостоятельности, устойчивости.

\section{Author's Field Data}

Expeditions to Baymaksky, Beloretsky, Burzyansky, and Kugarchinsky Districts (Republic of Bashkortostan, Russian Federation), 20032017. (In Bash.)

рико-этнографические очерки. Уфа: Китап, 2006. $376 \mathrm{c}$.

Салмин 1998 - Салмин A. K. Семантика дома у чувашей. Чебоксары: Чуваш. гос. ин-т гум. наук, 1998. 64 с.

Токарев 1970 - Токарев С. А. К методике этнографического изучения материальной культуры // Советская этнография. 1970. № 4. C. 3-17.

Толеубаев 2000 - Толеубаев А. Юрта в представлениях, верованиях и обрядах казахов // Кочевое жилище народов Средней Азии и Казахстана. М.: Наука, 2000. С. 165-178.

Ураксин $2000-$ Ураксин 3. Г. Этнолингвистический аспект слова в башкирском языке // Ядкяр. 2000. № 1. С. 73-77.

Хисамитдинова $2010-$ Хисамитдинова Ф. Г. Мифологический словарь башкирского языка. М.: Наука, 2010. 452 с.

Шараева 2020 - Шараева Т. И. Сакральный код в пространстве традиционного жилища у калмыков // Oriental Studies. 2020. Т. 13. № 1. C. 41-54. DOI: 10.22162/2619-09902020-47-1-41-54

Шитова 1984 - Шитова С. Н. Традиционные поселения и жилища башкир. Вторая половина XIX - первая четверть XX в. М.: Наука, 1984. $254 \mathrm{c}$.

Юсупов 2010 - Юсупов Р. М. Башкирская юрта: происхождение и основные этапы развития // Башкирская юрта. Методическое пособие / Р. М. Юсупов, Р. А. Султангареева, С. Н. Шитова. Уфа: ИИЯЛ УНЦ РАН, 2010. C. 5-16.

Янбухтина 1993 - Янбухтина А. Г. Народные традиции в убранстве башкирского дома. Уфа: Китап, 1993. 136 с. 


\section{References}

Baiburin A. K. House in Rituals and Representations of East Slavs. Leningrad: Nauka, 1983. 191 p. (In Russ.)

Bakaeva E. P., Sangadzhiev Yu. I. Dwelling Culture: Ethnic Traditions and Contemporary Priorities among Kalmyks. Elista: Dzhangar, 2005. 196 p. (In Russ.)

Bikbulatov N. V. et al. The Bashkirs: Ethnic History and Traditional Culture. R. Yusupov (ed.). Ufa: Bashkirskaya Entsiklopediya, 2002. 248 p. (In Russ.)

Bikbulatov N. V., Fatykhova F. F. Family and Household Life of Bashkirs, 19th-20th Centuries. Moscow: Nauka, 1991. 189 p. (In Russ.)

Georgi I. G. Bashkirs. In: Description of Russia’s Peoples, Their Household Rites, Customs, Faiths, and Other Peculiarities. Part Two: Tatar Peoples and Other Yet Unidentified Tribes of Northern Siberia. St. Petersburg: Imperial Academy of Sciences, 1799. P. 106. Available at: http://elib.shpl.ru/ru/nodes/14951-ch-2o-narodah-tatarskogo-plemeni-i-drugih-nereshennogo-esche-proishozhdeniya-severnyhsibirskih-1799\#mode/inspect/page/134/zoom/5 (accessed: October 30, 2021). (In Russ.)

Kalimullin B. G. Bashkir Villages: Planning and Construction. Ufa: Bashkortostan Book Publ., 1959. 108 p. (In Russ.)

Khisamitdinova F. G. A Bashkir Mythological Dictionary. Moscow: Nauka, 2010. 452 p. (In Bash. and Russ.)

Radlov V. V. From Siberia: Pages of the Diary. K. Tsivina, B. Chistova (transl.); S. Vainshtein (comment., afterword). Moscow: GRVL, 1989. 749 p. (In Russ.)

Rudenko S. I. The Bashkirs: Historical and Ethnographic Essays. Ufa: Kitap, 2006. 376 p. (In Russ.)

Salmin A. K. Semantics of Chuvash House. Cheboksary: Chuvash State Institute for the Humanities, 1998. 64 p. (In Russ.)

Sharaeva T. I. Sacred code in the space of Kalmyk traditional dwelling. Oriental Studies. 2020. Vol. 13. No. 1. Pp. 41-54. (In Russ.) DOI: 10.22162/2619-0990-2020-47-1-41-54

Shitova S. N. Bashkir Traditional Settlements and Dwellings, 1850s - 1920s. Moscow: Nauka, 1984. 254 p. (In Russ.)

Tokarev S. A. Ethnographic research of material culture: Methodology revisited. Sovetskaya etnografiya. 1970. No. 4. Pp. 3-17. (In Russ.)

Toleubaev A. Yurt in representations, beliefs and rites of Kazakhs. In: Nomadic Dwelling among Peoples of Central Asia Kazakhstan. Moscow: Nauka, 2000. Pp. 165-178. (In Russ.)

Uraksin Z. G. Ethnolinguistic aspect of Bashkir word. Yadkyar. 2000. No. 1. Pp. 73-77. (In Russ.)

Yanbukhtina A. G. Bashkir House: Folk Traditions in Interior Design. Ufa: Kitap, 1993. 136 p. (In Russ.)

Yusupov R. M. Bashkir yurt: Origin and main evolution stages. In: Yusupov R. M. et al. Bashkir Yurt. Ufa: Institute of History, Language and Literature (UFRS RAS), 2010. Pp. 5-16. (In Russ.)

Zhukovskaya N. L. Nomads of Mongolia: Culture, Traditions, Symbols. Moscow: Vostochnaya Literatura, 2002. 247 p. (In Russ.) 